\title{
DEPRESSION AND METABOLIC SYNDROME: TWO SIDES OF THE SAME COIN
}

\author{
George John, \\ Mona Asghari², \\ Vipin VP3, \\ Valsamma Eapen, ${ }^{2,4}$ \\ Cygnet Hospital Godden Green, \\ Sevenoaks, \\ United Kingdom \\ ${ }^{2}$ Mental Health Centre, \\ Liverpool Hospital, \\ Sydney. \\ Australia \\ ${ }^{3}$ Aster Medicity, \\ Kochi, \\ India \\ 4Infant Child and Adolescent \\ Psychiatry, \\ UNSW School of Psychiatry, \\ Sydney, \\ Australia
}

\author{
Corresponding Author: \\ Valsamma Eapen \\ Academic Unit of Child Psychiatry. \\ South West Sydney (AUCS), \\ Mental Health Centre, \\ Liverpool Hospital \& Ingham Institute \\ New South Wales, 2170 (Sydney) \\ Australia \\ e-mail:v.eapen@unsw.edu.au
}

Received: May 07, 2019

Revision received: July 03, 2019

Accepted: July 30, 2019

\begin{abstract}
Summary
This aim of this review was to examine the relationship between metabolic syndrome (MetS) and depression, which is complex and multifaceted with many inter-related factors including genetics, lifestyle factors, environmental factors and other psychological factors at play. There is some evidence to suggest that depression may lead to the development of cardiovascular disease through its association with MetS. It has also been suggested that depressive symptoms may be a consequence rather than the cause of the MetS, as obesity and dyslipidemia have been shown as predictive of depressive symptoms. Thus, the relationship between MetS and depression seems to be a two-way street and bidirectional just as the two sides of the same coin.
\end{abstract}

Key words: metabolic syndrome, depression, obesity, development, resistance

\section{Introduction}

Metabolic syndrome (MetS) and depression are both considered to be major public health problems worldwide, and both of these conditions are among the diseases with a high disease burden. Some studies have found a strong association between depression and MetS [1-8]. While patients who suffer from depression have been found to have a two-fold increased risk of developing MetS [4, 9-11] one study [12] showed that those who suffered from twelve weeks of 'chronic stress' developed depressive symptoms, which over time became comorbid with insulin resistance. There is general agreement that insulin resistance is one of the principal contributing factors in the development of MetS. However, it has also been found at the same time that the sedentary lifestyle of patients with depression [13] and the use of antipsychotic medication is also closely associated with the MetS [14-16]. As a result, from such findings, it has been recommended that it is essential to screen patients who suffer from depression for features of MetS [17, 18]. Due to the association between MetS and depression, the potential importance of screening patients with MetS for depression is becoming increasingly recognised by psychiatrists and endocrinologists alike.

Further, while the prevalence of MetS has 
dramatically increased in the general population in the last few decades and it has also increased in those with mental illnesses $[19,20]$ studies have revealed a bidirectional association between depression and MetS [19, 21, 22].

At the same time, there are also studies that have shown that depressive symptoms are present in patients with MetS in both childhood and adulthood [21] and that there is a bi-directional relationship between obesity and depression [23]. Obesity continues to be considered as the principal contributing factor in the development of the MetS and the psychosocial factors such as social stigma leading to discrimination further resulting in distress could also lead to depression [24]. Systematic reviews on MetS and depression have found a higher prevalence of depression in patients with MetS than others $[21,22]$. Thus, the relationship between the two conditions is starting to generate much research interest because both conditions pose significant public health challenges [22], and this review aimed to elucidate this.

\section{What is MetS?}

MetS refers to the clustering of several cardiovascular risk factors, which includes insulin resistance, atherogenic dyslipidemia, central obesity and systemic hypertension. All these conditions are interrelated and share underlying mediators, mechanisms and pathways [25]. Although the criteria for the definition of MetS vary slightly between the World Health Organisation (WHO) [26], National Cholesterol Education Program and Adult Treatment Panel III (NCEP ATP III) [27], European Group for the Study of Insulin Resistance (EGIR) [28] and the International Diabetes Federation (IDF) $[29,30]$, there is general agreement that MetS is defined as a clustering of abnormalities that include systemic hypertension, impaired glucose metabolism (impaired fasting glucose or presence of type 2 diabetes), impaired lipid metabolism (low high-density lipoprotein or HDL, and hypertriglyceridemia) as well as central obesity (high waist-to-hip ratio). Out of the various criteria, the NCEP ATP III criteria are the most widely used criteria for the diagnosis of metabolic syndrome. It uses measurements and laboratory results that are readily available to physicians, making it easy to use for clinical and epidemiological purposes [25]. As per updated NCEP ATP III criteria [31] MetS is considered to be present when at least 3 of the five criteria are satisfied (Table 1).

Table 1. Updated NCEP ATP III criteria for the diagnosis of metabolic syndrome [30]

\begin{tabular}{ll}
\hline Criteria & Definition \\
\hline Abdominal obesity & Waist circumference over $\geq 102 \mathrm{~cm}$ in men or $\geq 88 \mathrm{~cm}$ in women \\
\hline Elevated triglycerides & $\geq 150 \mathrm{mg} / \mathrm{dL}$, or drug treatment for high triglycerides \\
\hline Low HDL-cholesterol & $<40 \mathrm{mg} / \mathrm{dL}$ in men or $<50 \mathrm{mg} / \mathrm{dL}$ in women; or drug treatment for low \\
& HDL-C \\
\hline Elevated Blood Pressure & $\begin{array}{l}\text { Systolic } \geq 130 \mathrm{mmHg} \text { and } / \text { or diastolic } \geq 85 \mathrm{mmHg} \text { or drug treatment for } \\
\text { hypertension }\end{array}$ \\
\hline Elevated fasting plasma glucose & $\geq 100 \mathrm{mg} / \mathrm{dL} ;$ or drug treatment for elevated glucose \\
\hline
\end{tabular}

The practical utility of MetS concept is identifying patients with high risk of developing type 2 diabetes mellitus or cardiovascular disease with a shared pathophysiology, so that these population can be offered lifestyle modifications such as diet control, increasing physical activity, avoidance of smoking and appropriate pharmacological management of the individual components of MetS to reduce their cardiovascular disease risk [24].

\section{Mediators of MetS}

Although there is no single contributing factor for MetS, many researchers have recently suggested that visceral obesity is the primary determinant of insulin resistance that leads to MetS [32-35]. However, studies within the last couple of decades have also shown an association between MetS and psychosocial factors. [9, 11, 36-38] It has also been suggested that a tendency for a sedentary lifestyle is also found in both depression and MetS [39] and 
that the side effects to medications [40] also contribute to central obesity [41] and insulin resistance $[42,43]$. Besides, research has shown that the neuroendocrine effects of depression could increase the accumulation of abdominal fat [41] and interfere with the blood pressure (BP) regulation and glucose metabolism [44].

On the other hand, patients with MetS are found to have a preference for a sedentary lifestyle and their self-perception of low esteem, in turn, can lead to an increased risk of depression [42, 45]. It has further been observed and noted that patients with MetS had increased leptin resistance [46], which could again lead to a depressed mood [47]. Thus, it could be said that both depression and MetS have shared pathophysiology concerning central obesity and insulin resistance.

\section{Psychosocial factors as mediators for MetS}

While there is no single cause for MetS [31] all available evidence in literature seem to suggest that psychosocial factors including personality characteristics and stressful life events are predictive of notable changes and abnormalities in metabolic parameters as well as a risk for cardiovascular disease and related morbidity and mortality [11, 36, 48]. Several psychosocial mechanisms come into play in determining this association between the psychosocial factors and characteristics of MetS. And in that regard, symptoms of depression, together with frequent feelings of anger and irritability, has been shown to be predictive of an increased risk for MetS over an average of 7.4 years, while marital dissatisfaction, divorce and widowhood has also been shown to be predictive of an increased risk, over an 11.5-year period. The same group of investigators in a subsequent [11] evaluated a cohort of women who did not have MetS to start with, to see if psychosocial factors that are related to cardiovascular disease and type 2 diabetes can prospectively predict the risk for MetS in them. Also, they found that the risk of MetS in the group that was studied varied between 1.21 to 2.12-fold increase, in those with more severe depressive symptoms and or very stressful life events. The researchers further found that in those at the baseline and were symptomless to start with, reported feeling frequently and more intensely angry, tense or stressed and they too had an increased risk of developing MetS. However, another study [49] observed that MetS, while associated with depression, was not associated with psychological distress or anxiety.

\section{Overlapping pathophysiology}

Both drug treatment for depression and a sedentary lifestyle that is commonly associated with depression, can lead to weight gain and eventually to MetS. Further, there is a growing interest in the co-morbidity in mental and physical illnesses and the effects on each other as well as the associated physiological, emotional and hormonal factors that mediate their interrelationships [2, 50-54]. As patients with MetS are at increased risk of developing mood disorders, common pathways for depression, abdominal obesity and glucose metabolism have been proposed with overlapping genetic, environmental and lifestyle factors. For example, psychosocial antecedents that are commonly associated with adverse health choices such smoking and noncompliance with treatment are more common among those from lower socioeconomic and disadvantaged backgrounds who are also likely to succumb to increased life stresses.

Furthermore, stress and psychosocial factors related to it, have been shown to be associated with the physiological changes attributable to the onset and development of MetS. These physiological changes include changes in the functioning of the autonomic nervous system characterised by sympathetic arousal, elevated heart rate and BP and a dysregulation of the hypothalamic-pituitary-adrenocortical system. These changes lead to elevated cortisol and glucocorticoid levels, resulting in central obesity and hyperinsulinism, as well as altered inflammatory and haemopoietic processes such as heightened platelet aggregation, fibrinogen, pro-inflammatory cytokines and white blood cell count [55]. Also, some of these physiological changes have been linked to changes in the neurotransmitter system such as serotonin that is involved in mediating depressive and other negative emotions, which in turn has been associated with MetS. It is possible that although the activation of the hypothalamic-pituitaryadrenal (HPA) axis leads to behavioural as well 
as peripheral changes with beneficial effects in adjusting the homeostasis and thus improving the chances of survival, it is the arousal of the corticotrophin-releasing hormone $(\mathrm{CRH})$ and the locus coeruleus-norepinephrine autonomic (LC/NE) system along with it that leads to the other complex metabolic changes [56].

Another interesting possibility is that both psychological attributes (such as anxiety and depression) and the risk factors for MetS share a common genetic underpinning with environmental and external factors determining the course and eventual outcome of both conditions. In connection with this, the role of innate and genetic versus external and lifestyle factors was investigated in an Omani population [57]. They estimated the chances of inheriting the determinants of MetS versus the environmental factors and found that while aspects such as body weight, body mass index (BMI) and HDL levels had significant genetic influences, other aspects such as insulin resistance, abdominal obesity, diastolic BP and triglyceride levels, had significant environmental influences. From the results of this single study, it would seem that genetic and lifestyle, as well as environmental factors, act in concert in the development of MetS.

\section{Depression and MetS: cause or effect?}

It could be said that the relationship between depression and MetS, is a bi-directional one which cannot be fully explained by lifestyle and external risk factors alone, as it has been shown to persist even after controlling for these external factors [21, 22, 42, 58, 59]. Further, both cross-sectional and cohort studies have shown a higher incidence of depression in those with MetS compared to those without MetS $[3,21,60]$. Concerning this, it is also worth noting that childhood overweight and obesity that continues into adulthood has a significant impact on both the physical and psychological health of the individual. Further, those with a major depressive illness have been shown to have an increased risk of developing obesity and vice versa. Studies that have examined the phenomenology, co-morbidity, family history, biological and hormonal factors implicated in mood disorders and obesity have shown that both conditions share many similarities. Given the role of an unhealthy lifestyle (including smoking, poor dietary choices and an inactive lifestyle) in the aetiology, the role of the overlapping pathophysiological mechanisms in the course of both conditions are important considerations. The negative impact of poor compliance to treatment programs on the prognosis is also to be considered in the context of psychosocial factors and mood disorders such as depression that may co-exist with MetS because these factors have a special place in the comprehensive management of these patients.

\section{Conclusions}

Cardio-metabolic health concerns in patients with both MetS and depression are expected to increase in the coming years. Available evidence from the literature suggests that a two-way relationship exists between MetS and depression in terms of the pathogenetic processes in so far as each of these two conditions may be contributing to the other. Identifying the determinants of both depression and MetS is therefore critical because both can predict chronic health problems in the future. Thus routine screening of all patients with MetS for depression and those with depression for MetS is vital for early detection and intervention that can lead to a better outcome.

\section{Acknowledgements}

There is no financial support, and the review is not part of any funded projects.

\section{References}

1. Hartley TA, Knox SS, Fekedulegn D, BarbosaLeiker C, Violanti JM, Andrew ME, et al. Association between depressive symptoms and metabolic syndrome in police officers: results from two cross-sectional studies. J Environ Public Health. 2012;2012:861219.

2. Heiskanen TH, Niskanen LK, Hintikka JJ, Koivumaa-Honkanen HT, Honkalampi KM, Haatainen KM, et al. Metabolic syndrome and depression: a cross-sectional analysis. J Clin Psychiatry. 2006;67(9):1422-7.

3. Kamrowska A, Kamrowski C. [Depression in metabolic syndrome]. Pol Merkur Lekarski. 2012;33(194):117-9. Polish.

4. Kinder LS, Carnethon MR, Palaniappan LP, 
King AC, Fortmann SP. Depression and the metabolic syndrome in young adults: findings from the Third National Health and Nutrition Examination Survey. Psychosom Med. 2004;66(3):316-22.

5. Smith TW, Eagle DE, Proeschold-Bell RJ. Prospective associations between depressive symptoms and the metabolic syndrome: the Spirited Life Study of methodist pastors in North Carolina. Ann Behav Med. 2017;51(4):610-9.

6. Vaccarino V, McClure C, Johnson BD, Sheps DS, Bittner V, Rutledge T, et al. Depression, the metabolic syndrome and cardiovascular risk. Psychosom Med. 2008;70(1):40-8.

7. Vogelzangs N, Beekman AT, Boelhouwer IG, Bandinelli S, Milaneschi Y, Ferrucci L, et al. Metabolic depression: a chronic depressive subtype? Findings from the InCHIANTI study of older persons. J Clin Psychiatry. 2011;72(5):598-604.

8. Vogelzangs N, Suthers K, Ferrucci L, Simonsick EM, Ble A, Schrager M, et al. Hypercortisolemic depression is associated with the metabolic syndrome in late-life. Psychoneuroendocrinology. 2007;32(2):151-9.

9. Goldbacher EM, Matthews KA. Are psychological characteristics related to risk of the metabolic syndrome? A review of the literature. Ann Behav Med. 2007;34(3):240-52.

10. McElroy SL, Keck PE Jr. Metabolic syndrome in bipolar disorder: a review with a focus on bipolar depression. J Clin Psychiatry. 2014;75(1):46-61.

11. Räikkönen K, Matthews KA, Kuller LH. Depressive symptoms and stressful life events predict metabolic syndrome among middleaged women: a comparison of World Health Organization, Adult Treatment Panel III, and International Diabetes Foundation definitions. Diabetes care. 2007;30(4):872-7.

12. Su W-J, Peng W, Gong H, Liu Y-Z, Zhang Y, Lian YJ, et al. Antidiabetic drug glyburide modulates depressive-like behavior comorbid with insulin resistance. J Neuroinflammation. 2017;14(1):210.

13. Hallgren M, Herring MP, Owen N, Dunstan D, Ekblom Ö, Helgadottir B, et al. Exercise, physical activity, and sedentary behavior in the treatment of depression: broadening the scientific perspectives and clinical opportunities. Front Psychiatry. 2016;7:36.

14. Akgün S, Köken T, Kahraman A. Evaluation of adiponectin and leptin levels and oxidative stress in bipolar disorder patients with metabolic syndrome treated by valproic acid. J Psychopharmacol. 2017;31(11):1453-9.

15. Sajatovic M, Kales HC, Mulsant BH. Prescribing antipsychotics in geriatric patients: focus on schizophrenia and bipolar disorder. Current Psychiatry. 2017;16(10):20-6.

16. Skibinska M, Kapelski P, Pawlak J, RajewskaRagerA, Dmitrzak-WeglarzM, Szczepankiewicz A, et al. Glial Cell Line-Derived Neurotrophic Factor (GDNF) serum level in women with schizophrenia and depression, correlation with clinical and metabolic parameters. Psychiatry Res. 2017;256:396-402.

17. De Hert M, Schreurs V, Sweers K, Van Eyck D, Hanssens L, Šinko S, et al. Typical and atypical antipsychotics differentially affect long-term incidence rates of the metabolic syndrome in first-episode patients with schizophrenia: a retrospective chart review. Schizophr Res. 2008;101(1-3):295-303.

18. Yumru M, Savas HA, Kurt E, Kaya MC, Selek S, Savas E, et al. Atypical antipsychotics related metabolic syndrome in bipolar patients. J Affect Disord. 2007;98(3):247-52.

19. Allison DB, Newcomer JW, Dunn AL, Blumenthal JA, Fabricatore AN, Daumit GL, et al. Obesity among those with mental disorders: a National Institute of Mental Health meeting report. Am J Prev Med. 2009;36(4):341-50.

20. Zimmet PZ, McCarty DJ, de Courten MP. The global epidemiology of non-insulin-dependent diabetes mellitus and the metabolic syndrome. J Diabetes Complications. 1997;11(2):60-8.

21. Akbaraly $\mathrm{TN}$, Kivimäki $\mathrm{M}$, Brunner $\mathrm{EJ}$, Chandola T, Marmot MG, Singh-Manoux A, et al. Association between metabolic syndrome and depressive symptoms in middle-aged adults: results from the Whitehall II study. Diabetes care. 2009;32(3):499-504.

22. Pan A, Keum N, Okereke OI, Sun Q, Kivimaki M, Rubin RR, et al. Bidirectional association between depression and metabolic syndrome: a systematic review and meta-analysis of epidemiological studies. Diabetes care. 2012;35(5):1171-80.

23. Kaner G, Koyu EB, Kürklü NS, Adıgüzel KT. SUN-P ${ }_{249}$ : The relationship between body mass index, abdominal obesity, metabolic parameters and depression among Reproductive aged women. Clin Nutr. 2017;36(1):S146.

24. Trainer S, Brewis A, Wutich A, Han SY. Obesity, depression, and weight-related stigma syndemics. In: Foundations of BioSocial Health: stigma and illness interactions. 1st ed. 83-106. Lanham: Lexington Books, 2017.

25. Huang PL. A comprehensive definition for metabolic syndrome. Dis Models Mech. 2009;2(5-6):231-7.

26. Alberti KG, Zimmet PZ. Definition, diagnosis and classification of diabetes mellitus and 
its complications. Part 1: diagnosis and classification of diabetes mellitus. Provisional report of a WHO consultation. Diabet Med. 1998;15(7):539-53.

27. Expert Panel on Detection, Evaluation, and Treatment of High Blood Cholesterol in Adults. Executive summary of The Third Report of The National Cholesterol Education Program (NCEP) Expert Panel on detection, evaluation, and treatment of high blood cholesterol in adults (Adult Treatment Panel III). JAMA. 2001;285(19):2486-97.

28. Balkau B, Charles MA. Comment on the provisional report from the WHO consultation. European Group for the Study of Insulin Resistance (EGIR). Diabet med. 1999;16(5):442-3.

29. Alberti K, Eckel R, Grundy S, Zimmet P, Cleeman J, Donato K, et al. Harmonizing the metabolic syndrome: a joint interim statement of the International Diabetes Federation Task Force on Epidemiology and Prevention; National Heart, Lung, and Blood Institute; American Heart Association; World Heart Federation; International Atherosclerosis Society; and International Association for the Study of Obesity. Circulation. 2009;120(16):1640-5.

30. Zimmet P, Magliano D, Matsuzawa Y, Alberti G, Shaw J. The metabolic syndrome: a global public health problem and a new definition. J Atheroscler Thromb. 2005;12(6):295-300.

31. Grundy SM, Cleeman JI, Daniels SR, Donato KA, Eckel RH, Franklin BA, et al. Diagnosis and management of the metabolic syndrome: an American Heart Association/National Heart, Lung, and Blood Institute scientific statement: Executive Summary. Circulation. 2005;4(4):198-203.

32. Escobedo N, Oliver G. The lymphatic vasculature: its role in adipose metabolism and obesity. Cell Metab. 2017;26(4):598-609.

33. Saltiel AR, Olefsky JM. Inflammatory mechanisms linking obesity and metabolic disease. J Clinl Invest. 2017;127(1):1-4.

34. Singer K, Lumeng CN. The initiation of metabolic inflammation in childhood obesity. J Clin Invest. 2017;127(1):65-73.

35. Tran BT, Jeong BY, Oh J-K. The prevalence trend of metabolic syndrome and its components and risk factors in Korean adults: results from the Korean National Health and Nutrition Examination Survey 2008-2013. BMC Public Health. 2017;17(1):71.

36. Chandola T, Brunner E, Marmot M. Chronic stress at work and the metabolic syndrome: prospective study BMJ. 2006;332(7540):521-5.
37. Lidfeldt J, Nyberg P, Nerbrand C, Samsioe G, Scherstén B, Agardh CD. Socio-demographic and psychosocial factors are associated with features of the metabolic syndrome. The Women's Health in the Lund Area (WHILA) study.. Diabetes Obes Metab. 2003;5(2):106-12.

38. Räikkönen K, Matthews KA, Kuller LH. The relationship between psychological risk attributes and the metabolic syndrome in healthy women: antecedent or consequence? Metabolism. 2002;51(12):1573-7.

39. Steinberg T, Harush A, Barnea M, Dar R, Piacentini J, Woods D, et al. Tic-related cognition, sensory phenomena, and anxiety in children and adolescents with Tourette syndrome. Compr Psychiatry. 2013;54(5):4626.

40. McIntyre RS, Danilewitz M, Liauw SS, Kemp DE, Nguyen HT, Kahn LS, et al. Bipolar disorder and metabolic syndrome: an international perspective. J Affect Disord. 2010;126(3):36687.

41. $\mathrm{Xu}$ Q, Anderson D, Lurie-Beck J. The relationship between abdominal obesity and depression in the general population: A systematic review and meta-analysis. Obes Res Clin Pract. 2011;5(4):e267-360.

42. Luppino FS, de Wit LM, Bouvy PF, Stijnen T, Cuijpers P, Penninx BW, et al. Overweight, obesity, and depression: a systematic review and meta-analysis of longitudinal studies. Arch Gen Psychiatry. 2010;67(3):220-9.

43. Mezuk B, Eaton WW, Albrecht S, Golden SH. Depression and type 2 diabetes over the lifespan: a meta-analysis. Diabetes care. 2008;31(12):2383-90.

44. Anagnostis P, Athyros VG, Tziomalos K, Karagiannis A, Mikhailidis DP. Clinical review: the pathogenetic role of cortisol in the metabolic syndrome: a hypothesis. J Clin Endocrinol Metab. 2009;94(8):2692-701.

45. Hatzenbuehler ML, Keyes KM, Hasin DS. Associations between perceived weight discrimination and the prevalence of psychiatric disorders in the general population. Obesity (Silver Spring). 2009;17(11):2033-9.

46. Patel SB, Reams GP, Spear RM, Freeman RH, Villarreal D. Leptin: linking obesity, the metabolic syndrome, and cardiovascular disease. Curr Hypertens Rep. 2008;10(2):131-7.

47. Schiepers OJ, Wichers MC, Maes M. Cytokines and major depression. Prog Neuropsychopharmacol Biol Psychiatry. 2005;29(2):201-17.

48. Laaksonen DE, Lakka H-M, Salonen JT, Niskanen LK, Rauramaa R, Lakka TA. Low levels of leisure-time physical activity and 
cardiorespiratory fitness predict development of the metabolic syndrome. Diabetes care. 2002;25(9):1612-8.

49. Dunbar JA, Reddy P, Davis-Lameloise N, Philpot B, Laatikainen T, Kilkkinen A, et al. Depression: an important comorbidity with metabolic syndrome in a general population. Diabetes care. 2008;31(12):2368-73.

50. Butnoriene J, Bunevicius A, Norkus A, Bunevicius R. Depression but not anxiety is associated with metabolic syndrome in primary care based community sample. Psychoneuroendocrinology. 2014;40:269-76.

51. Chang H-C, Hsiao T-M, Lien M-H, Yeh C-J, Yang H-J. Metabolic syndrome and depression are not correlated: results from a community sample exploring the unique and common correlates for the two diseases. Neuropsychiatry (London). 2017;7(2):142-8.

52. García-Toro M, Vicens-Pons E, Gili M, Roca M, Serrano-Ripoll MJ, Vives M, et al. Obesity, metabolic syndrome and Mediterranean diet: impact on depression outcome. J Affect Disord. 2016;194:105-8.

53. Goldberg RJ, Weng FL, Kandula P. Acute and chronic allograft dysfunction in kidney transplant recipients. Med Clin North Am. 2016;100(3):487-503.

54. Virtanen M, Ferrie JE, Akbaraly T, Tabak A, Jokela M, Ebmeier KP, et al. Metabolic syndrome and symptom resolution in depression: A 5-year follow-up of older adults. J Clin Psychiatry. 2017;78(1):e1-e7.
55. Brunner E, Hemingway H, Walker BR, Page M, Clarke P, Juneja M, et al. Adrenocortical, autonomic, and inflammatory causes of the metabolic syndrome: nested case-control study. Circulation. 2002;106(21):2659-65.

56. Chrousos GP. The role of stress and the hypothalamic-pituitary-adrenal axis in the pathogenesis of the metabolic syndrome: neuroendocrine and target tissue-related causes. Int J Obes Relat Metab Disord. 2000;24 Suppl 2:S50-5.

57. Bayoumi RA, Al-Yahyaee SA, Albarwani SA, Rizvi SG, Al-Hadabi S, Al-Ubaidi FF, et al. Heritability of determinants of the metabolic syndrome among healthy Arabs of the Oman family study. Obesity (Silver Spring). 2007;15(3):551-6.

58. Golden SH, Lazo M, Carnethon M, Bertoni AG, Schreiner PJ, Roux AV, et al. Examining a bidirectional association between depressive symptoms and diabetes JAMA. 2008;299(23):2751-9.

59. Rethorst CD, Leonard D, Barlow CE, Willis BL, Trivedi MH, DeFina LF. Effects of depression, metabolic syndrome, and cardiorespiratory fitness on mortality: results from the Cooper Center longitudinal study. Psychol Med. 2017;47(14):2414-20.

60. Ghanei Gheshlagh R, Parizad N, Sayehmiri $\mathrm{K}$. The relationship between depression and metabolic syndrome: systematic review and meta-analysis study. Iran Red Crescent Med J. 2016;18(6):e26523. 